\title{
Analysis of Learning Losses of Students During the COVID-19 Pandemic
}

\author{
Sergei P. Zhdanov ${ }^{1^{*}}$ \\ (1) 0000-0002-1330-8165
}

Kseniia M. Baranova ${ }^{2}$

(1) 0000-0002-2740-1643

Natalia Udina ${ }^{3}$

(D) 0000-0002-4945-7605

\section{Artem E. Terpugov 4}

(D) 0000-0002-2528-5060

\section{Elena V. Lobanova ${ }^{5}$}

(D) 0000-0003-2822-8392

\section{Oksana V. Zakharova ${ }^{6}$}

(1) 0000-0003-3728-963X

${ }^{1}$ Department of State and Legal Disciplines, Plekhanov Russian University of Economics, Moscow, RUSSIA

${ }^{2}$ Institute of Foreign Languages, Moscow City University, Moscow, RUSSIA

${ }^{3}$ Department of Foreign Languages, RUDN University, Moscow, RUSSIA

${ }^{4}$ Federal Center for Educational Legislation, Moscow, RUSSIA

${ }^{5}$ Russian New University (RosNOU), Moscow, RUSSIA

${ }^{6}$ I.M. Sechenov First Moscow State Medical University, Moscow, RUSSIA

*Corresponding author: zhdanov120009@yandex.ru

Citation: Zhdanov, S. P., Baranova, K. M., Udina, N., Terpugov, A. E., Lobanova, E. V., \& Zakharova, O. V. (2022). Analysis of Learning Losses of Students During the COVID-19 Pandemic. Contemporary Educational Technology, 14(3), ep369. https://doi.org/10.30935/cedtech/11812

\section{ARTICLE INFO}

Received: 3 Sep 2021

Accepted: 7 Feb 2022

\section{ABSTRACT}

The COVID-19 outbreak has wreaked havoc on educational systems on a scale never seen before in history. The closure of schools and other institutions of learning has impacted $94 \%$ of the world's student population. Even school closures, such as those that occur during the summer, have a significant effect on children's academic ability. The word "learning loss" refers to any loss of information and abilities, whether specific or generic. By Fall 2020, extended absences from school will have a detrimental effect on student achievement. Learning loss is commonly addressed when schools close for extended periods of time during the summer, natural catastrophes, or epidemics. Even brief school closures might result in significant loss of learning. Due to the global nature of the COVID-19 epidemic, special attention was devoted to learning losses.

During the pandemic, learning loss occurs as a result of kids studying at home due to school closures. School closures do not have to result in an equal loss of learning for all students. The variables that contribute to learning loss include "change in teaching methods", "opportunities to reach education", "less time for learning", and "emotional factors". Reduced instructional time-provided by teachers in accordance with the national curriculum-is likely to result in loss of learning. Due to the disparate scales used in the studies, it is hard to compare the magnitudes of learning losses. However, based on the data from the studies, it is reasonable to assume that these nations are investigating learning losses and that they exist. As a result, there is convincing evidence that students lose more information during lockdown than they do over the course of a normal school year. The elements causing learning losses differ according to context. With the reopening of schools, it is important to establish the actual magnitude of learning losses and to implement remedial measures in order to avoid the emergence of medium- and long-term educational difficulties.

Keywords: learning losses, change in teaching methods, opportunities to reach education, less time for learning, less control/feedback, emotional factors

Copyright $\odot 2022$ by authors; licensee CEDTECH by Bastas, CY. This article is an open access article distributed under the terms and conditions of the Creative Commons Attribution License (http://creativecommons.org/licenses/by/4.0/). 


\section{INTRODUCTION}

The COVID-19 epidemic has caused the most significant disruption to educational systems in history, affecting almost 1.6 billion learners in more than 190 nations across all continents and causing widespread panic. Closing of schools and other learning places has had an influence on $94 \%$ of the world's student population (United Nations, 2020). Students' academic skills and perseverance have been shown to be negatively impacted by school disruptions (Alexander et al., 2007; Belot \& Webbink, 2010; Haeck \& Lefebvre, 2020). Students are subjected to such negative impacts not just when schools are closed due to unforeseen events, but also when teachers are absent for a certain amount of time. Even school closures, such as those over the summer months, have a severe impact on children's academic abilities.

Closures are frequently associated with significant "learning losses", which have been recorded in North America, Western Europe and Africa, among other places (Alexander et al., 2007; Andrabi et al., 2021; Angrist et al., 2020b; Cooper et al., 1996; Davies \& Aurini, 2013; Jaume \& Willén, 2019; Slade et al., 2017). According to The Glossary of Education Reform (2013):

"the term learning loss refers to any specific or general loss of knowledge and skills or to reversals in academic progress, most commonly due to extended gaps or discontinuities in a student's education."

Formal education - whether in-person or online-provides students with critical information and skills for growth and development. As a result, discontinuing formal schooling may have a detrimental effect on children's learning results (Bao et al., 2020).

The majority of children's formal education occurs in schools. Closing school buildings and relocating learning to a remote setting may result in students spending less time learning (Di Pietro et al., 2020). Educators, parents, and students have firsthand knowledge of the high cost of this lengthy period of distance learning, which includes higher rates of depression and anxiety as well as lost learning opportunities for children (Dorn et al., 2020). There is widespread worry about a lack of time spent on learning activities by students (Education Development Trust, 2020). A large number of kids reported a worryingly low level of studying at home during the school lockdown (2 hours or less each day). In contrast, slightly under a third of students indicated a moderately high degree of learning commitment ( 5 hours or more each day) (Huber \& Helm, 2020). As a result, huge disparities in study time at home across students.

The initial estimates concerning the consequences of school closures are based on previously gathered data about school disruptions and loss of teaching time, such as summer learning loss, teacher strikes, reforms, or natural disasters (Bao et al., 2020; Eyles et al., 2020; Frenette et al., 2020; Kuhfeld et al., 2020; Maldonado \& De Witte, 2021; Tugun et al., 2020). However, a new study shows that even brief school closures might result in substantial medium-term lost learning (Kaffenberger, 2021).

Kuhfeld and Tarasawa (2020) forecast COVID-19 average academic progress trajectory by grade, mathematics, and reading. According to preliminary COVID-19 slide estimates, children will return in autumn 2020 with about $70 \%$ of the reading improvements in a regular school year. In mathematics, kids typically return with less than half of the learning gains and under certain grades, over a year behind what we would expect in normal settings. Preliminary predictions confirm many educators' fears: extended absences from school will negatively influence student progress come autumn 2020. It's time for practitioners and policymakers to act on COVID-19. When schools resume, we must be ready to help children who are likely academically behind.

According to Clark et al. (2021), there is still no empirical data on the influence of online education on student performance while schools are physically shut down. In this context, this study aims to analyze perspectives on "learning losses" that are considered to exist, may occur and are anticipated based on published publications and reports.

\section{What Is Learning Loss?}

"Learning loss" is defined as any specific or general loss of knowledge and skills or withdrawals in academic progress (The Glossary of Education Reform, 2013). Learning loss is frequently discussed when schools are 


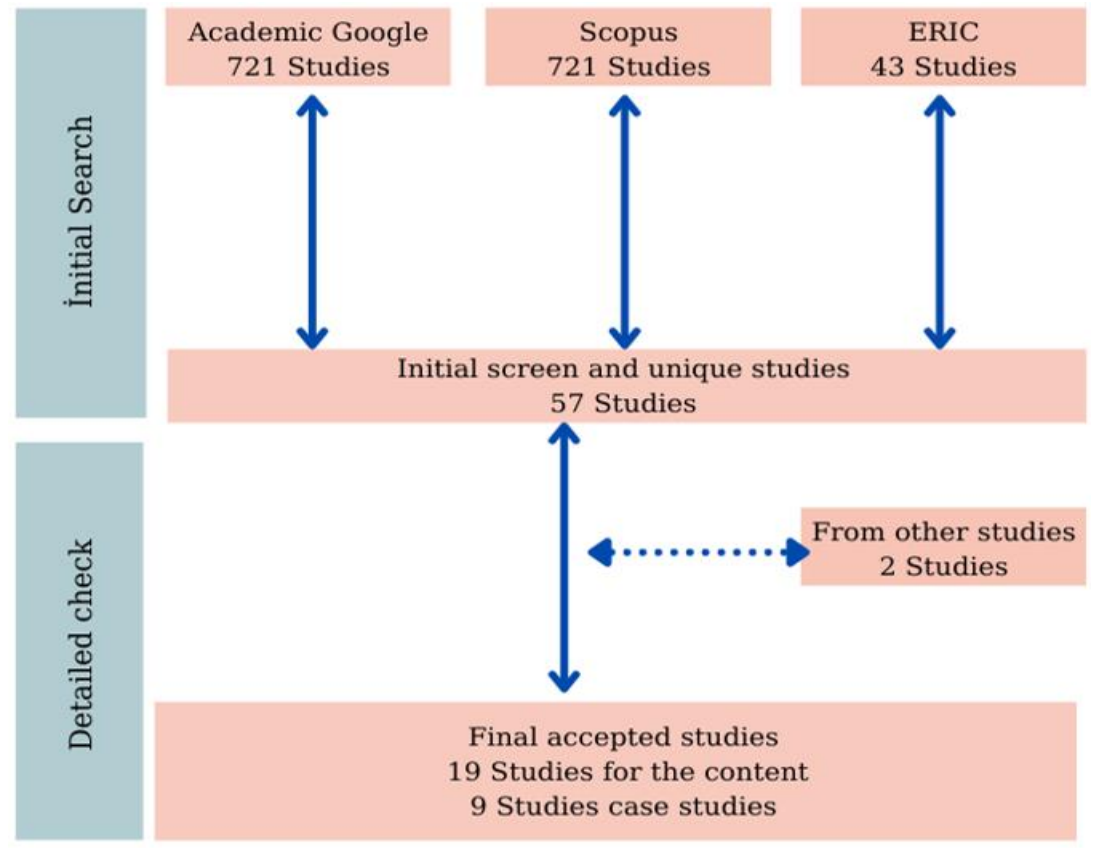

Figure 1. Review process

temporarily closed during summer periods, natural disasters, and epidemics. The closures will result in significant learning losses (Kaffenberger, 2021; Kuhfeld et al., 2020; The World Bank, 2020). It is also regarded essential because of its tremendous effect. Since the COVID pandemic is worldwide, extra significance was paid to learning losses. Many national and international organizations (Elliot Major et al., 2021; Geven \& Hasan, 2020; The World Bank, 2020; United Nations, 2020) have issued reports on learning losses.

Researchers (Dorn et al., 2020; Kurniawan \& Budiyono, 2021) described learning loss during the pandemic as follows: "The gap is currently widening and there is a lack of student involvement because students are studying at home as a result of school closures." Additionally, according to studies, kids will be unable to complete a proper education during the pandemic phase (Angrist et al., 2020b; Frenette et al., 2020; Kurniawan \& Budiyono, 2021). School closures do not have to result in the same amount of lost learning for every student. According to Haeck and Lefebvre (2020), some students lose a lot of ground, while others gain some ground.

\section{METHOD}

The focus of the study is to collect and interpret studies related to the learning losses of students during the COVID-19. The study is a mini literature review. While gathering data, the snowball method was employed. The terms "learning loss" and "academic loss" were searched for in the Google Scholar, Scopus, and ERIC databases in order to find research published between the years 2020-2021. Next, the data from the research was reviewed to see if it contained data from the COVID-19 era. In the end, also, papers and reports providing direct data were discovered through an examination of the references of the studies found. Finally, there are nine studies that give direct information about students' learning records. Also, there are 19 studies for findings for learning losses. Figure 1 shows our review process.

\section{Data Analysis}

To begin, the results of 19 researches on "learning losses" were analyzed. The researchers separately read the excerpts. The researchers deliberated and assigned names to the themes. The researchers agreed on the following themes: "change in teaching methods", "opportunities to reach education", "less time for learning", "less control/feedback", and "emotional factors". The relevant extracts and studies are mentioned. We determined the relevant data from the studies from which are decided as case studies. Data on "learning losses" were determined and collated in these investigations. In the "Case Studies on Learning Losses" section, we will discuss the findings of these studies. 


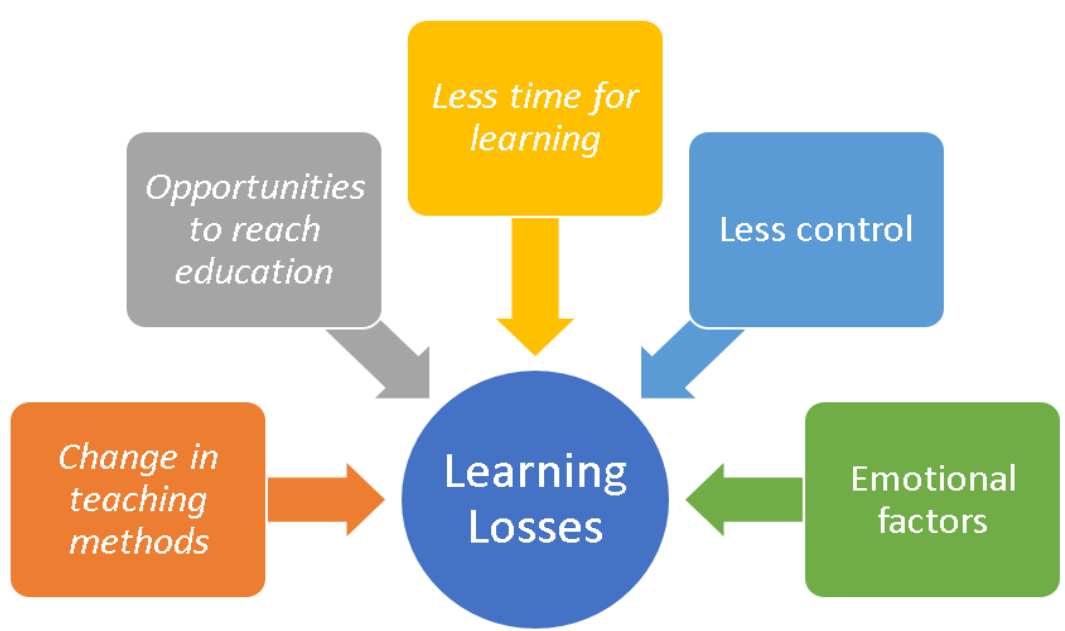

Figure 2. Affecting factors to learning losses during COVID-19

\section{FINDINGS}

\section{The Factor Affecting Learning Loss}

The factors impacting learning losses in various settings may vary. However, the factors impacting the pandemic-related learning losses may be represented as "change in teaching methods", "opportunities to reach education", "less time for learning", "less control/feedback" and "emotional factors". Figure 2 depicts the affecting factors to learning losses during COVID-19.

\section{Change in teaching methods}

To avoid learning losses as a result of school closures caused by COVID-19, it is advised that every effort be made to utilize distant learning programs in addition to open learning applications and platforms deemed suitable by schools and instructors (Shuja et al., 2020). However, the majority of instructors (66.9\%) were required for the first time to teach online (Di Pietro et al., 2020). It is extremely difficult to replace the learning interactions that occur between teachers and students in the classroom with technology (Education Endowment Foundation, 2020). The lack of familiarity with the distant education system among students, particularly those in the younger age groups, may have resulted in learning losses.

Providing access to education via technology, on the other hand, has the potential to have a small-tomoderately beneficial effect on learning during school closures (Education Endowment Foundation, 2020). But whether this effect can compensate for learning losses is an important question to be answered.

\section{Opportunities to reach education}

Research on online learning and teaching reveals that they are effective only if students have consistent access to the internet and computers and if teachers have gotten focused training and supports for online instruction (García \& Weiss, 2020). The availability of remote learning possibilities for students during the COVID epidemic differed significantly from one school to the next (Azubuike et al., 2021). Additionally, many instructors experienced difficulty in obtaining technology (computers, software, reliable internet connection, etc.) (Di Pietro et al., 2020).

Due to the closure of schools, children who do not have access to online learning materials or suitable equipment may be unable to engage in a variety of learning-based activities (Frenette et al., 2020). Schools help students from all income backgrounds about equally. While performance among children with a higher socioeconomic position continues to improve at times when school is not in session (such as summer vacations), no such improvement is found among children with a lower socioeconomic status (Di Pietro et al., 2020; Haeck \& Lefebvre, 2020). To compensate for lost learning in the absence of school, high-income families have access to alternate forms of instruction-books, computers, the Internet, radio, television, and smartphones-that many low-income families do not (Angrist et al., 2020a; Bacher-Hicks et al., 2021). 


\section{Less time for learning}

The majority of students receive their official education in schools. By closing schools and moving learning to a remote location, kids may spend less time learning (Di Pietro et al., 2020). The reduction in instructional time-given by instructors according to the national curriculum against which students will ultimately be evaluated-is likely to result in significant learning losses (Andrew et al., 2020).

According to a research by Champeaux et al. (2020) conducted in Italy and France, students in both nations have diverted a significant portion of their time previously spent to education to passive screen usage during the lockdown period. Less time spent in learning might result in learning loss (Di Pietro et al., 2020). According to the findings of a research of students' time spent on activities during the school day, time spent on learning is less than total time spent in and out of school in the period of May 2020, compared to 2014-2015 data (Andrew et al., 2020).

Students from higher-income households with more educated parents spent more time studying during school closures, had better study equipment at home, and received more assistance (Andrew et al., 2020). Children shut down at home in the UK spend an average of only 2.5 hours each day completing schoolwork. This proportion is approximately half that predicted by a prior poll, showing that learning losses are considerably larger than expected (Green, 2020).

\section{Less control/feedback}

At all stages of education, the quality and specificity of feedback on learning progress is critical (Rouleau et al., 2021). From a cognitive standpoint, feedback is frequently viewed as a source of information necessary for task improvement (Wisniewski et al., 2020). Students are getting very little control/feedback during COVID19 (Huber \& Helm, 2020). Even a small amount of additional time spent with parents, however, can have a beneficial effect on a child's development, especially in young children (Andrew et al., 2020).

Another issue is whether the level of participation of the students in the activities at home during the distance education process is controlled or not. Rather of enhancing students' self-regulation, volitional, and motivational abilities, as well as parents' control over learning time, COVID-19 basically eliminates instructor control overactive learning time. Approximately three-quarters of youngsters reported that their parents do not always exert control over them (Huber \& Helm, 2020).

Parents who did not support their children's remote learning cited a lack of knowledge, being too busy, having someone else do it, or the expense. Although the replies of parents are not mutually exclusive, 38 percent indicated that they were not supporting their children's distant learning because they lacked the necessary skills. 35\% reported being too busy to assist their children with distant learning (Azubuike et al., 2021). Many working parents struggled to educate, control, and care for their children during the lengthy school closure (Kuhfeld et al., 2020).

\section{Emotional factors}

Human cognitive functions such as perception, attention, learning, memory, reasoning, and problem solving are all significantly influenced by emotion. Emotions exert a disproportionately powerful impact on attention, altering its selectivity and driving action and behavior (Tyng et al., 2017). Severe anxiety might result in learning loss (Kurniawan \& Budiyono, 2021; Rai et al., 2021).

Educators, parents, and students have all seen personally the significant cost of this extended time of distant learning, which includes increased rates of depression and anxiety, as well as a reduction in student learning outcomes (Dorn et al., 2020).

\section{Case Studies on Learning Losses}

In Botswana, the low-tech intervention is planned to compensate the learning losses during COVID-19. The control group's mean learning level is 1.73 , indicating that the average student is unable to do subtraction correctly. A 0.29 standard deviation rise for the combined phone plus SMS group. A 0.16 standard deviation increase for the SMS-only group (Angrist et al., 2020b). Without the intervention, there would have been a learning loss of 0.29 standard deviations for all groups. 
The study is being performed to ascertain the effects of school closures on standardized exams administered in the 2020 academic year of primary school in Belgium's Dutch-speaking Flemish area. The 2020 cohort experienced significant learning losses in three out of five assessed subjects, with a 0.17 standard deviation decrease in school average mathematics scores and a 0.19 standard deviation decrease in school average Dutch scores (reading, writing, and language) compared to the previous cohort. The large effect sizes found appear to be a result of both lost learning progress and learning loss, rather than just lost progress (Maldonado \& De Witte, 2021).

In the Netherlands, standardized exams in arithmetic, spelling, and reading were examined for kids aged 8 to 11 years. Based on a composite score of pupils' performances in math, spelling, and reading, a baseline estimate of learning loss in 2020 compared to the preceding three years. Students lost an average of 3.16 percentile points, or 0.08 standard deviations, in the national distribution (SD) (Engzell et al., 2021).

In China, the three schools' differing instructional approaches (no assistance, online support with their instructors, and online support with the top instructors) during the COVID-19 epidemic provide a natural experiment for determining the causal impacts of online learning on students' academic success. Using the difference-in-differences (DID) technique, we demonstrate that online learning may increase student performance by 0.22 standard deviations when compared to students who lost access to learning support during the COVID-19 lockout. It has been demonstrated that students who do not get education suffer a learning loss of at least 0.22 standard deviation (Clark et al., 2021).

Summer papers taken by primary children in mainstream state schools in England during the Fall 2020 and compares them to the results received in Summer 2019 from the preceding cohort. Between 2019 and 2020 , there were significant declines in achievement across all topics and year groups. The biggest decreases were observed in math, specifically papers 2 and 3 taken by year 3 and 4 children in 2020. However, GPS (grammar, punctuation, and spelling) scores have decreased significantly each year as well. To put these findings into context, typical standardized scores for these individual papers were between 103 and 106 in Summer 2019 and have historically seldom varied by more than 0.5-point year over year. In 2020, year-onyear reductions of 5-10 points, sometimes more is recorded (Cohen, 2020).

In the United States of America, based on these findings from a comparison of the 2011 and 2020 kindergarten reading scales, the model estimated that children whose parents read to them every day will gain 10.6 points between 1 January and 1 September 2020 as a result of COVID-19 school closures. In comparison, children whose parents are unable to read to them daily and those whose parents never read to them earn 8.3 and 5.2 points, respectively, during the same time period. In comparison to a business-as-usual situation without COVID-19 school closures, children who have their parents read to them every day would earn 3.2 points less, while those who do not have their parents would gain 5.5 points less (Bao et al., 2020). As a result, kindergarten kids learning lose at least 3.2 points.

According to data from the Curriculum Associates i-Ready Platform (USA), children in their sample only learned $67 \%$ of the arithmetic and $87 \%$ of the reading that grade-level classmates would have mastered by the autumn. Students lost the equivalent of three months of arithmetic learning (33\%) and one-and-a-half months of reading learning on average (13\%) (Dorn et al., 2020). Overall, learning capacity decreased significantly for all four nations as a result of school closures during the first lockdown in 2020. Scotland and Wales suffered the greatest learning losses, with children missing on average two-thirds (66\% and $64 \%$, respectively) of the lessons they would usually get. In England and Northern Ireland, the learning loss was slightly less severe, but still significant, at $57 \%$ and $59 \%$, respectively (Elliot Major et al., 2021).

The typical kid will lose between 0.3 and 0.8 years of learning-adjusted schooling due to school closures during the epidemic, according to estimates. Pakistani students spend an average of 9.1 years in school but owing to the poor quality of the education system, they only study for 5.1 years. According to calculations, by the time schools are completely reopened, this number might drop to between 4.8 and 4.3 years (Geven \& Hasan, 2020). As a result, learning losses are predicted to be between 0.8 and 0.3 years.

Due to the fact that the researches employ varying scales, it is impossible to compare magnitudes of learning losses. However, based on the studies data, it is expected that these nations are researching learning losses and that there are learning losses. Table 1 shows the comparison of research-based studies results related to learning losses. 
Table 1. Comparison of research-based studies results related to learning losses

\begin{tabular}{lccc}
\hline Research & Type & Country & Learning Losses \\
\hline Angrist et al. (2020b) & Working paper & Botswana & 0.29 Standard deviation \\
Maldonado and De Witte (2021) & Journal article & Belgium & 0.17 Standard deviation-Mathematics \\
& & & 0.19 Standard deviation-Dutch \\
Engzell et al. (2021) & Journal article & Netherlands & 0.08 Standard deviation \\
Clark et al. (2021) & Working paper & China & 0.22 Standard deviation \\
Blainey et al. (2020) & Report & England & 5-10 Points \\
Bao et al. (2020) & Journal article & USA & 3.2-5.5 Points \\
Dorn et al. (2020) & Report & USA & \%33-Mathematics/\%13-Reading \\
Elliot Major et al. (2021). & Report & UK & \%57-\%66 \\
Geven and Hasan (2020) & Report & Pakistan & $0.3-0.8$ Years \\
\hline
\end{tabular}

\section{DISCUSSION AND CONCLUSIONS}

According to related researches (Alexander et al., 2007; Andrabi et al., 2021; Angrist et al., 2020b; Cooper et al., 1996; Davies \& Aurini, 2013; Jaume \& Willén, 2019; Slade et al., 2017), school closures are frequently associated with significant "learning losses". The study is aimed to examine the learning losses of students during the COVID-19. Due to the shutdown of schools, children were forced to continue their education at home. According to Hanushek and Woessmann (2020), there is little research on the efficacy of home learning for the whole student population and what this means for skill development. However, evidence from many countries indicates that many youngsters received little effective teaching. For a sizable number of children, learning appears to have been almost non-existent during school closures.

Closures will result in considerable loss of learning (Kaffenberger, 2021; Kuhfeld et al., 2020; The World Bank, 2020). The elements that have an influence on learning losses in different contexts may differ. Changes in teaching techniques, along with the use of distance education, will have an effect on students' performance. Particularly when considering younger age groups, it is unavoidable that students will endure learning losses until they become accustomed to the instructional strategies, they are encountering for the first time (Frenette et al., 2020). Opportunities to get an education is affecting factor to learning losses. In many studies (Cenedese \& Spirovska, 2021; Nicolau et al., 2020; Putri et al., 2020), due to the lack of infrastructure, they cannot access education opportunities. According to Andrew et al. (2020), during pandemic periods, students have allocated less time for education. Devoting less time to learning will naturally affect educational outcomes. According to Huber and Helm (2020), students are getting very little control/feedback during COVID-19. However, feedback on learning progress has a keystone role (Rouleau et al., 2021). Students' learning at home cannot be controlled due to factors such as parents' work (Kuhfeld et al., 2020) or lack of sufficient knowledge (Azubuike et al., 2021). There are studies (Husky et al., 2020; Radwan et al., 2021) on when students' stress levels decrease during the pandemic period. Excessive stress and excitement are factors that prevent learning (Kurniawan \& Budiyono, 2021; Rai et al., 2021).

According to the findings of researches (Angrist et al., 2020b; Bao et al., 2020; Clark et al., 2021; Cohen, 2020; Dorn et al., 2020; Elliot Major et al., 2021; Engzell et al., 2021; Geven \& Hasan, 2020; Maldonado \& De Witte, 2021) done in a variety of nations throughout the world, there is more or less learning loss.

Distance education options have been proposed to partially compensate for and improve education throughout the pandemic period. "Learning losses" should be the primary focus of discussions when children return to school to "assist them in catching up on basic foundational skills." (Kaffenberger, 2021; The World Bank, 2020). The student-level approach to teaching is especially relevant when students are low and far behind grade-level expectations (Angrist et al., 2020b).

Adaptive education supplemented by technology did not produce statistically meaningful benefits for struggling readers (Neitzel et al., 2021). When online learning is given during a school lockdown, it has a beneficial effect on student success when the school ceases to provide any assistance (Maldonado \& De Witte, 2021).

The case studies described above demonstrate instances of detectable learning loss. However, this demonstrates another issue: a dearth of global research on the extent of learning losses. 
As a result, there is compelling evidence that pupils lose more knowledge during lockdown than they do throughout a regular school year. The factors affecting learning losses in various situations may vary. With the reopening of schools, it is critical to ascertain the precise volume of learning losses and to provide remedies in order to avert the creation of medium- and long-term educational issues.

Author contributions: All authors were involved in concept, design, collection of data, interpretation, writing, and critically revising the article. All authors approve final version of the article.

Funding: The authors received no financial support for the research and/or authorship of this article.

Declaration of interest: Authors declare no competing interest.

Data availability: Data generated or analysed during this study are available from the authors on request.

\section{REFERENCES}

Alexander, K. L., Entwisle, D. R., \& Olson, L. S. (2007). Lasting consequences of the summer learning gap. American Sociological Review, 72(2), 167-180. https://doi.org/10.1177/000312240707200202

Andrabi, T., Daniels, B., \& Das, J. (2021). Human capital accumulation and disasters: Evidence from the Pakistan earthquake of 2005. Journal of Human Resources. https://doi.org/10.3368/jhr.59.2.0520-10887r1

Andrew, A., Cattan, S., Costa Dias, M., Farquharson, C., Kraftman, L., Krutikova, S., Phimister, A., \& Sevilla, A. (2020). Inequalities in children's experiences of home learning during the COVID-19 lockdown in England. Fiscal Studies, 41(3), 653-683. https://doi.org/10.1111/1475-5890.12240

Angrist, N., Bergman, P., \& Matsheng, M. (2020a). School's out: Experimental evidence on limiting learning loss using "low-tech" in a pandemic. SSRN Electronic Journal, 28205. https://doi.org/10.2139/ssrn.3735967

Angrist, N., Bergman, P., Brewster, C., \& Matsheng, M. (2020b). Stemming learning loss during the pandemic: A rapid randomized trial of a low-tech intervention in Botswana. SSRN Electronic Journal, 44. https://doi.org/10.2139/ssrn.3663098

Azubuike, O. B., Adegboye, O., \& Quadri, H. (2021). Who gets to learn in a pandemic? Exploring the digital divide in remote learning during the COVID-19 pandemic in Nigeria. International Journal of Educational Research Open, 2, 100022. https://doi.org/10.1016/j.ijedro.2020.100022

Bacher-Hicks, A., Goodman, J., \& Mulhern, C. (2021). Inequality in household adaptation to schooling shocks: COVID-induced online learning engagement in real time. Journal of Public Economics, 193, 104345. https://doi.org/10.1016/j.jpubeco.2020.104345

Bao, X., Qu, H., Zhang, R., \& Hogan, T. P. (2020). Modeling reading ability gain in kindergarten children during COVID-19 school closures. International Journal of Environmental Research and Public Health, 17(17), 1-13. https://doi.org/10.3390/ijerph17176371

Belot, M., \& Webbink, D. (2010). Do teacher strikes harm educational attainment of students? Labour, 24(4), 391-406. https://doi.org/10.1111/j.1467-9914.2010.00494.x

Cenedese, M., \& Spirovska, I. (2021). Online education of marginalized children in North Macedonia and Italy during the COVID-19 pandemic. Dve Domovini [Two Homelands], 54, 103-115. https://doi.org/10.3986/ dd.2021.2.08

Champeaux, H., Piccoli, L., Mangiavacchi, L., \& Marchetta, F. (2020). Learning at home: Distance learning solutions and child development during the COVID-19 lockdown. IZA Institute of Labor Economics. https://www.iza.org/publications/dp/13819/learning-at-home-distance-learning-solutions-and-childdevelopment-during-the-covid-19-lockdown

Clark, A. E., Nong, H., Zhu, H., \& Zhu, R. (2021). Compensating for academic loss: Online learning and student performance during the COVID-19 pandemic. China Economic Review, 68, 101629. https://doi.org/ 10.1016/j.chieco.2021.101629

Cohen, D. (2020). The impact of lockdown on children: Attachment, mental health and resilience. In D. Cohen (Ed.), Surviving lockdown: Human nature in social isolation. Routledge. https://doi.org/10.4324/ 9781003105091-8

Cooper, H., Nye, B., Charlton, K., Lindsay, J., \& Greathouse, S. (1996). The effects of summer vacation on achievement test scores: A narrative and meta-analytic review. Review of Educational Research, 66(3), 227268. https://doi.org/10.3102/00346543066003227

Davies, S., \& Aurini, J. (2013). Summer learning inequality in Ontario. Canadian Public Policy, 39(2), $287-307$. https://doi.org/10.3138/CPP.39.2.287 
Di Pietro, G., Biagi, F., Costa, P., Karpiński, Z., \& Mazza, J. (2020). The likely impact of COVID-19 on education: Reflections based on the existing literature and recent international datasets. Publications Office of the European Union. https://publications.jrc.ec.europa.eu/repository/handle/JRC121071

Dorn, E., Hancock, B., Sarakatsannis, J., \& Viruleg, E. (2020). COVID-19 and learning loss-disparities grow and students need help. Mckinsey \& Company. https://www.mckinsey.com/industries/public-and-socialsector/our-insights/covid-19-and-learning-loss-disparities-grow-and-students-need-help

Education Development Trust. (2020). An international review of plans and actions for school reopening. In Education Development Trust. https://www.educationdevelopmenttrust.com/our-research-and-insights/ research/an-international-review-of-plans-and-actions-for-s

Education Endowment Foundation. (2020). Impact of school closures on the attainment gap: Rapid evidence assessment. Education Endowment Foundation. https://educationendowmentfoundation.org.uk/covid19-resources/best-evidence-on-impact-of-school-closures-on-the-attainment-gap

Elliot Major, L., Eyles, A., \& Machin, S. (2021). Learning loss since lockdown: Variation across the home nations. Center for Economic Performance. https://cep.Ise.ac.uk/_new/publications/abstract.asp?index=8228

Engzell, P., Frey, A., \& Verhagen, M. D. (2021). Learning loss due to school closures during the COVID-19 pandemic. PNAS, 118(17), e2022376118. https://doi.org/10.1073/PNAS.2022376118

Eyles, A., Gibbons, S., \& Montebruno, P. (2020). COVID-19 school shutdowns: What will they do to our children's education? Center for Economic Performance. https://cep.Ise.ac.uk/pubs/download/cepcovid-19-001.pdf

Frenette, M., Frank, K., \& Deng, Z. (2020). School closures and the online preparedness of children during the COVID-19 pandemic. Economic Insights, 1(103), 1-11.

García, E., \& Weiss, E. (2020). COVID-19 and student performance, equity, and U.S. education policy. Economic Policy Institute. https://www.epi.org/publication/the-consequences-of-the-covid-19-pandemic-foreducation-performance-and-equity-in-the-united-states-what-can-we-learn-from-pre-pandemicresearch-to-inform-relief-recovery-and-rebuilding/

Geven, K., \& Hasan, A. (2020). Learning losses in Pakistan due to COVID-19 school closures. World Bank Group. https://doi.org/10.1596/34659

Green, F. (2020). Schoolwork in lockdown: New evidence on the epidemic of educational poverty. LLAKES. https://www.Ilakes.ac.uk/wp-content/uploads/2021/03/RP-67-Francis-Green-Research-Papercombined-file.pdf

Haeck, C., \& Lefebvre, P. (2020). Pandemic school closures may increase inequality in test scores. Canadian Public Policy, 46(1), S82-S87. https://doi.org/10.3138/CPP.2020-055

Hanushek, E. A., \& Woessmann, L. (2020). The economic impacts of learning losses. OECD. https://www.oecdilibrary.org/education/the-economic-impacts-of-learning-losses_21908d74-en

Huber, S. G., \& Helm, C. (2020). COVID-19 and schooling: Evaluation, assessment and accountability in times of crises-reacting quickly to explore key issues for policy, practice and research with the school barometer. Educational Assessment, Evaluation and Accountability, 32(2), 237-270. https://doi.org/10.1007/ s11092-020-09322-y

Husky, M. M., Kovess-Masfety, V., \& Swendsen, J. D. (2020). Stress and anxiety among university students in France during COVID-19 mandatory confinement. Comprehensive Psychiatry, 102, 152191. https://doi.org/10.1016/j.comppsych.2020.152191

Jaume, D., \& Willén, A. (2019). The long-run effects of teacher strikes: Evidence from Argentina. Journal of Labor Economics, 37(4), 1097-1139. https://doi.org/10.1086/703134

Kaffenberger, M. (2021). Modelling the long-run learning impact of the COVID-19 learning shock: Actions to (more than) mitigate loss. International Journal of Educational Development, 81, 102326. https://doi.org/10.1016/j.ijedudev.2020.102326

Kuhfeld, M., \& Tarasawa, B. (2020). The COVID-19 slide: What summer learning loss can tell us about the potential impact of school closures on student academic achievement. NWEA Research. https://www.nwea.org/content/uploads/2020/05/Collaborative-Brief_Covid19-Slide-APR20.pdf

Kuhfeld, M., Soland, J., Tarasawa, B., Johnson, A., Ruzek, E., \& Liu, J. (2020). Projecting the potential impact of COVID-19 school closures on academic achievement. Educational Researcher, 49(8), 549-565. https://doi.org/10.3102/0013189X20965918

Kurniawan, H., \& Budiyono. (2021). Heroe's model: Case study to reduce students' learning loss and anxiety. Cypriot Journal of Educational Sciences, 16(3), 1122-1140. https://doi.org/10.18844/cjes.v16i3.5830 
Maldonado, J. E., \& De Witte, K. (2021). The effect of school closures on standardised student test outcomes. British Educational Research Journal. https://doi.org/10.1002/berj.3754

Nicolau, C., Henter, R., Roman, N., Neculau, A., \& Miclaus, R. (2020). Tele-education under the COVID-19 crisis: Asymmetries in Romanian education. Symmetry, 12(9), 1-18. https://doi.org/10.3390/sym12091502

Putri, R. S., Purwanto, A., Pramono, R., Asbari, M., Wijayanti, L. M., \& Hyun, C. C. (2020). Impact of the COVID19 pandemic on online home learning: An explorative study of primary schools in Indonesia. International Journal of Advanced Science and Technology, 29(5), 4809-4818.

Radwan, E., Radwan, A., Radwan, W., \& Pandey, D. (2021). Perceived stress among school students in distance learning during the COVID-19 pandemic in the Gaza Strip, Palestine. Augmented Human Research, 6, 12. https://doi.org/10.1007/s41133-021-00050-6

Rai, S., Akhtar, Z., Singh, K. K., Bhatt, M. L. B., Verma, S. K., \& Kar, S. K. (2021). Academic loss-related anxiety among college students during COVID-19 pandemic. Indian Journal of Health Sciences and Biomedical Research, 14, 239-244.

Rouleau, K., Abla, C., Gibson, T., \& Simenson-Gurolnick, J. (2021). Digital lessons learned: How the online pivot of 2020 can make teaching and learning better forever. McREL International. https://eric.ed.gov/ ?q=source\%3A\%22mcrel\%22\&id=ED611354

Shuja, A., Shuja Sana Khan, A., \& Bakht, M. I. (2020). Global effects of COVID-19 educationally and various strategies to minimize the academic loss. International Journal of Education, Management and Social Science Studies Volume, 1(1), 1-14.

Slade, T. S., Piper, B., Kaunda, Z., King, S., \& Ibrahim, H. (2017). Is 'summer' reading loss universal? Using ongoing literacy assessment in Malawi to estimate the loss from grade-transition breaks. Research in Comparative and International Education, 12(4), 461-485. https://doi.org/10.1177/1745499917740657

The Glossary of Education Reform. (2013). Learning loss. https://www.edglossary.org/learning-loss/

The World Bank. (2020). The COVID-19 pandemic: Shocks to education and policy responses. https://openknowledge.worldbank.org/bitstream/handle/10986/33696/148198.df?sequence=4

Tugun, V., Bayanova, A. R., Erdyneeva, K. G., Mashkin, N. A., Sakhipova, Z. M., \& Zasova, L. V. (2020). The opinions of technology supported education of university students. International Journal of Emerging Technologies in Learning, 15(23), 4-14. https://doi.org/10.3991/ijet.v15i23.18779

Tyng, C. M., Amin, H. U., Saad, M. N. M., \& Malik, A. S. (2017). The influences of emotion on learning and memory. Frontiers in Psychology, 8, 1454. https://doi.org/10.3389/fpsyg.2017.01454

United Nations. (2020). Policy brief: Education during COVID-19 and beyond. https://unsdg.un.org/resources/ policy-brief-education-during-covid-19-and-beyond

Wisniewski, B., Zierer, K., \& Hattie, J. (2020). The power of feedback revisited: A meta-analysis of educational feedback research. Frontiers in Psychology, 10, 3087. https://doi.org/10.3389/fpsyg.2019.03087

\section{$\bullet *$}

